\title{
Avaliação do potencial de argilas de Sergipe e Alagoas na produção de agregados para uso em concreto
}

\section{(Potential assessment of Sergipe and Alagoas clays in aggregates production for use in concrete)}

\author{
H. A. Oliveira ${ }^{1}$, C. P. Santos ${ }^{1}$, R. M. P. B. Oliveira ${ }^{1,2}$, E. de Jesus ${ }^{3}$, Z. S. Macedo ${ }^{1,4}$ \\ ${ }^{1}$ Programa de Pós-graduação em Ciência e Engenharia de Materiais, \\ ${ }^{2}$ Departamento de Ciência e Engenharia de Materiais \\ ${ }^{3}$ Departamento de Engenharia Química, \\ ${ }^{4}$ Departamento de Física, Universidade Federal de Sergipe, São Cristóvão, SE \\ herbetalves148@gmail.com,cochiran@hotmail.com,rosaneboliveira@gmail.com, \\ edilsonjs@ufs.br,zelia.macedo@gmail.com
}

\begin{abstract}
Resumo
O presente trabalho teve por objetivo caracterizar tecnologicamente três argilas utilizadas em setores de cerâmica no estado de Sergipe, Brasil. Sua potencialidade para produzir agregado sintético de argila calcinada para substituir britas na produção de concreto foi avaliada. As argilas foram caracterizadas por ensaios de granulometria, índice de plasticidade, difração de raios $\mathrm{X}$, análise térmica diferencial e gravimétrica, análise dilatométrica, fluorescência de raios $\mathrm{X}$, teor de matéria orgânica, capacidade de troca de cátions, área específica e microscopia eletrônica de varredura para análise do tamanho e morfologia de grãos. Corpos de prova foram produzidos por prensagem uniaxial a $30 \mathrm{MPa}$, em formato retangular e cilíndrico. Os corpos de prova das argilas e também de formulações cerâmicas foram queimados e posteriormente caracterizados em ensaios de absorção de água, densidade aparente, resistência mecânica à compressão e morfologia de grão. Foi observado que, após queima a $1120^{\circ} \mathrm{C}$, duas das formulações apresentaram parâmetros de resistência mecânica à compressão, absorção de água e massa específica comparáveis aos da brita usada em concreto leve.
\end{abstract}

Palavras-chave: argila, agregado sintético, caracterização tecnológica, cerâmica.

Abstract

This study aims to characterize technologically three clays employed by ceramic industries in Sergipe state, Brazil. Its potential use for the production of calcined synthetic aggregate to substitute gravel in concrete production was evaluated. The characterization of the clays included particle size and plasticity analysis, X-ray diffraction, differential and thermogravimetric analyses, dilatometry, $X$-ray fluorescence, organic matter content, cation exchange capacity, specific area, and scanning electron microscopy. Ceramic bodies were uniaxially pressed under $30 \mathrm{MPa}$, into rectangular and cylindrical shapes. Ceramic bodies of individual clays and also ceramic formulations were fired and subsequently characterized to determine their water absorption, apparent density, compressive strength, and grain morphology. It was observed that, after firing at $1120^{\circ} \mathrm{C}$, two formulations presented strength, water absorption and specific mass comparable to those of gravel used in concrete.

Keywords: clay, synthetic aggregate, technological characterization, ceramics.

\section{INTRODUÇÃO}

O Brasil consome anualmente cerca de 300 milhões de toneladas de brita na fabricação de concreto [1,2]. A extração de brita, no entanto, traz impactos ambientais relacionados à retirada da vegetação, escavações, movimentação de terra, causando modificação da paisagem local. Além disso, o uso de explosivos no desmonte de rocha e a etapa de produção dos agregados causam vibração do terreno e emissões de partículas para a atmosfera, sobretudo eliminação de $\mathrm{CO}_{2}$ [3]. Em locais onde a brita não está à disposição para uso, devido à falta de jazidas, utiliza-se o seixo rolado de rios na fabricação de concreto. É o caso da região amazônica do Brasil, onde grande parte dos maciços foi formada gerando sedimentos inconsolidados de pequena textura, tais como areia, silte e argila. Porém, a extração do seixo de rio também traz danos ambientais, com a degradação visual das paisagens e assoreamento dos rios [4, 5].

$\mathrm{O}$ uso de agregado sintético produzido a partir da argila calcinada apresenta-se como uma alternativa ao uso de britas em obras civis. Este tipo de agregado sintético, se produzido com qualidade comparável à das britas naturais, pode trazer uma diminuição dos impactos ambientais causados pela extração predatória de seixo rolado e de rochas [6]. A emissão de gases para a atmosfera decorrente da queima da argila na produção dos agregados pode ser contornada através do uso de filtros e catalisadores [4], como já vem sendo empregado em fornos comerciais. As argilas para 
produção de agregado sintético devem ser sedimentares, de boa plasticidade e com sinterização na faixa de temperaturas de 1000 a $1300{ }^{\circ} \mathrm{C}$ [7-9]. São argilas que se enquadram nas características das argilas utilizadas nos setores de cerâmica tradicional, cujas reservas no Brasil são grandes, as quais se destacam a indústria de revestimento cerâmico e cerâmica vermelha.

No ano de 2014 o segmento de revestimento cerâmico no Brasil, representado por 93 empresas, ocupou o segundo lugar mundial no consumo de revestimento com 853,2 milhões de metros quadrados [10]. Adicionalmente, o segmento de cerâmica vermelha, que é formado por cerca de 6900 estabelecimentos fabris, registrou reservas de argilas capazes de fornecer cerca de 5,3 bilhões de toneladas [11]. O objetivo do presente trabalho é produzir agregados a partir de argila calcinada com propriedades tecnológicas como resistência mecânica à compressão, absorção de água e massa específica próximos de uma brita, conforme especificações apresentadas na Tabela I, de modo que possam ser utilizados na produção de concreto leve ou usos afins. O estudo foi realizado a partir de argilas utilizadas nos segmentos de revestimento cerâmico e cerâmica vermelha do estado de Sergipe e Alagoas, Brasil.

\section{METODOLOGIA}

Na Fig. 1 são mostrados os depósitos de argilas identificados como PIN-1, IN-2 e MA-3, localizados nos

Tabela I - Especificações de britas para produção de concreto [12]. [Table I - Specification of gravel for concrete production [12].]

\begin{tabular}{cccc}
\hline Tipo & $\mathrm{Me}\left(\mathrm{kg} / \mathrm{m}^{3}\right)$ & $\mathrm{AA}(\%)$ & TRC $(\mathrm{MPa})$ \\
\hline Gnaisse & 2750 a 2900 & 0,2 a 2,0 & 180 a 250 \\
Granito & 2600 a 3000 & 0,2 a 0,4 & 160 a 240 \\
\hline
\end{tabular}

Me - massa específica; $A A$ - absorção de água; TRC - tensão de ruptura à compressão.

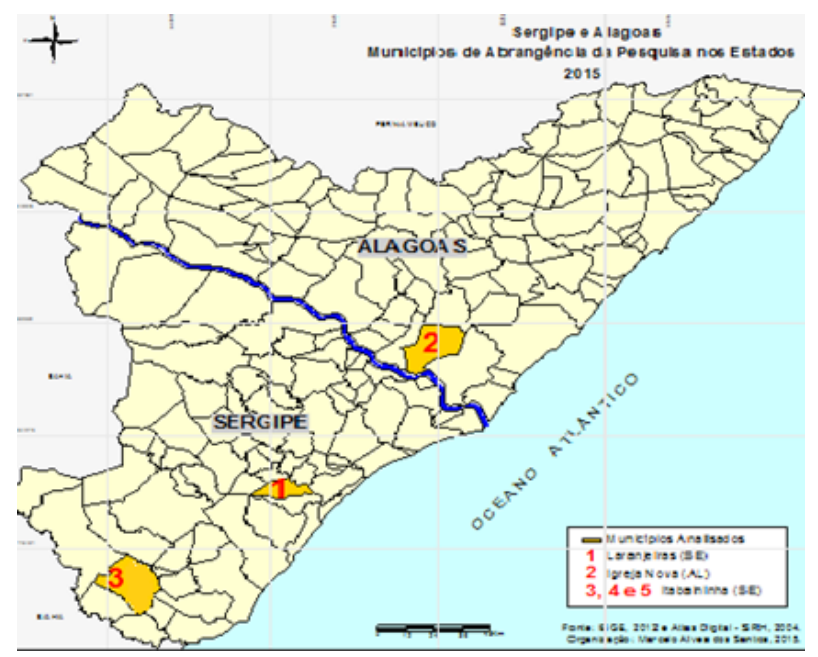

Figura 1: Localização dos depósitos de argila dos estados de Sergipe e Alagoas, Brasil [13].

[Figure 1: Location of clay deposits in Sergipe and Alagoas States, Brazil [13].] estados de Sergipe e Alagoas, e que foram utilizados no presente estudo.

Preparação das amostras: as amostras foram quarteadas, secas ao ar e depois em estufa a $40 \pm 10{ }^{\circ} \mathrm{C}$ por $48 \mathrm{~h}$. Em seguida sofreram redução granulométrica por meio de moinho de martelo com abertura de grelha de 2 $\mathrm{mm}$. Uma amostra foi separada de cada argila e passada em peneira ABNT $200(0,074 \mathrm{~mm})$ para realização de ensaios de caracterização e em peneira ABNT $60(0,250$ $\mathrm{mm}$ ) para ensaios tecnológicos. Distribuição do tamanho de partículas: foi realizada pelo método de peneiramento seguido de sedimentação em conformidade com a norma ASTM D422 [14]. Análise química por FRX: os percentuais dos óxidos constituintes das amostras foram determinados através de medidas semiquantitativas pela técnica de espectrometria por fluorescência de raios X (FRX). As medidas foram realizadas em vácuo, em um equipamento da Bruker, S4 Pioneer, utilizando amostras com massa em torno de $10 \mathrm{~g}$ que foram prensadas no formato de corpos cilíndricos com diâmetro de $20 \mathrm{~mm}$ e espessura de $3 \mathrm{~mm}$, aproximadamente. Limites de Atterberg, limites de liquidez (LL) e de plasticidade ( $L P$ ): foram obtidos de acordo com a NBR 6459 [15] e a NBR 7180 [16], respectivamente. O índice de plasticidade (IP) é o resultado da diferença entre os limites de liquidez e plasticidade, segundo a equação:

$$
\mathrm{IP}=\mathrm{LL}-\mathrm{LP}
$$

Perda ao fogo (P.F.): foi medida pela diferença das massas antes e após a queima a $1000^{\circ} \mathrm{C}$ em forno com patamar de 20 min. Capacidade de troca de cátions (CTC): a troca iônica foi determinada pelo método do azul de metileno de acordo com a norma ASTM 837-1992 [17], sendo que a partir deste resultado foi possível determinar a área específica BET pela equação:

$$
\mathrm{BET}=\mathrm{CTC} \times 7,85
$$

Matéria orgânica: foi determinada por meio do processo de calcinação a $440{ }^{\circ} \mathrm{C}$. A matéria orgânica pode influenciar no aumento da plasticidade das argilas, aumentando a compactação, dificultando a eliminação da água livre bem como a desidroxilação, podendo gerar deformações nas peças. O teor de matéria orgânica foi determinado segundo a norma ASTM D 2974 [18]. Análise térmica diferencial e gravimétrica DTA-TGA: os eventos térmicos apresentados no intervalo de 25 e $1200{ }^{\circ} \mathrm{C}$ foram registrados em medidas simultâneas de DTA e TGA. As medidas foram realizadas em um equipamento da TA Instruments, SDT 2960. As amostras foram medidas em cadinho de platina, sob fluxo de ar sintético com vazão de $100 \mathrm{~mL} / \mathrm{min}$ e taxa de aquecimento de $10^{\circ} \mathrm{C} / \mathrm{min}$. Caracterização mineralógica: a difratometria de raios $\mathrm{X}$ foi utilizada para a identificação das fases cristalinas de acordo com os padrões obtidos no banco de dados do ICSD (Inorganic Crystal Structure Database) e os porcentuais de fases das composições mineralógicas foram estimados através do software Match versão Demo. 
Os padrões de difração foram obtidos com um equipamento Rigaku D-MAX 100 usando radiação $\mathrm{CuK} \alpha_{1}(\lambda=1,5418 \AA)$ em modo de varredura contínua, em intervalo angular de 3 a $80^{\circ} \mathrm{com}$ velocidade de varredura de $1 \% \mathrm{~min}$. Para confirmação da fase montmorilonita, uma amostra de PIN foi saturada com etileno glicol com fim de observar o deslocamento da distância interplanar, sendo que foi utilizado o intervalo de varredura de 2 a $15^{\circ}$. Análise dilatométrica: as medidas dilatométricas foram realizadas para verificar as alterações dimensionais de expansão e retração térmica e o processo de densificação até $1150^{\circ} \mathrm{C}$ de amostras compactadas em um molde cilíndrico de $12 \mathrm{~mm}$ x $6 \mathrm{~mm}$ de dimensão. Foi utilizado um dilatômetro da Netzsch, DIL 402PC, com fluxo ar sintético e vazão de 130 $\mathrm{mL} / \mathrm{min}$ variando da temperatura ambiente até $1150{ }^{\circ} \mathrm{C}$ com taxa de aquecimento de $10{ }^{\circ} \mathrm{C} / \mathrm{min}$. Medidas de densidade: o processo de densificação foi determinado como uma função da temperatura de queima até $1150^{\circ} \mathrm{C}$ a partir da relação com a retração linear obtida nos ensaios de dilatometria (Equação C), no qual se considera que a contração é isotrópica [19]:

$$
\rho=\rho_{0} /\left(1-\Delta \mathrm{L} / \mathrm{L}_{0}\right)^{3}
$$

Preparação das massas e ensaios de caracterização: as argilas foram umidificadas com umidade de cerca de $8 \%$ e passadas na peneira ABNT $16(1,2 \mathrm{~mm})$ para ajuste da granulometria para conformação. Foram conformados corpos de prova retangulares com dimensões de $62 \mathrm{~mm} \mathrm{x}$ $50 \mathrm{~mm}$ x $12 \mathrm{~mm}$ e outros cilíndricos com dimensões de 20 $\mathrm{mm} \times 20 \mathrm{~mm}$ em uma prensa manual com pressão uniaxial de compactação de $30 \mathrm{MPa}$. Os corpos de prova foram secos inicialmente ao ar livre por $24 \mathrm{~h}$ e depois em estufa a $100 \pm 5^{\circ} \mathrm{C}$ até massa constante. A etapa de queima foi realizada em forno da Jung, LF 0612, a 900, 1000 e $1100{ }^{\circ} \mathrm{C}$ para argilas e 1080 , 1100 e $1120^{\circ} \mathrm{C}$ para formulações de massa, a uma taxa de $20^{\circ} \mathrm{C} / \mathrm{min}$ com patamar de $15 \mathrm{~min}$ na maior temperatura. Após caracterização das argilas, foram preparadas formulações de massa baseando-se em misturas binárias e ternárias nas mesmas condições em que as amostras individuais foram preparadas, visando-se obter uma absorção de água próxima de zero. As misturas binárias foram preparadas calculando-se as proporções dos componentes na mistura final mediante as Equações D e E, sendo $X_{1}+X_{2}=1[20]$ :

$$
\begin{aligned}
& \mathrm{AA}_{\mathrm{m}}=\mathrm{X}_{1} \cdot \mathrm{AA}_{1}+\mathrm{X}_{2} \mathrm{AA}_{2} \\
& \mathrm{AA}_{\mathrm{m}}=\mathrm{X}_{1} \mathrm{AA}_{1}+\left(1-\mathrm{X}_{1}\right) \cdot \mathrm{AA}_{2}
\end{aligned}
$$

A Fig. 2 mostra um diagrama ternário de [21], adaptada de Riley, com definição de uma região onde se encontra a composição em que ocorre formação de fase líquida suficiente para se atingir a densificação máxima podendo provocar expansão em um agregado produzido a partir de argila. $\mathrm{O}$ diagrama ternário contempla $\mathrm{SiO}_{2}, \mathrm{Al}_{2} \mathrm{O}_{3}$ e óxidos fundentes $\left(\mathrm{Na}_{2} \mathrm{O}, \mathrm{K}_{2} \mathrm{O}, \mathrm{Fe}_{2} \mathrm{O}_{3}, \mathrm{CaO}, \mathrm{MgO}\right.$ e $\left.\mathrm{TiO}_{2}\right)$. Todas as formulações foram dentro dessa faixa, indicando que possuíam composição química para produzir fase líquida para atingir a densificação máxima, exceto as formulações C e D.

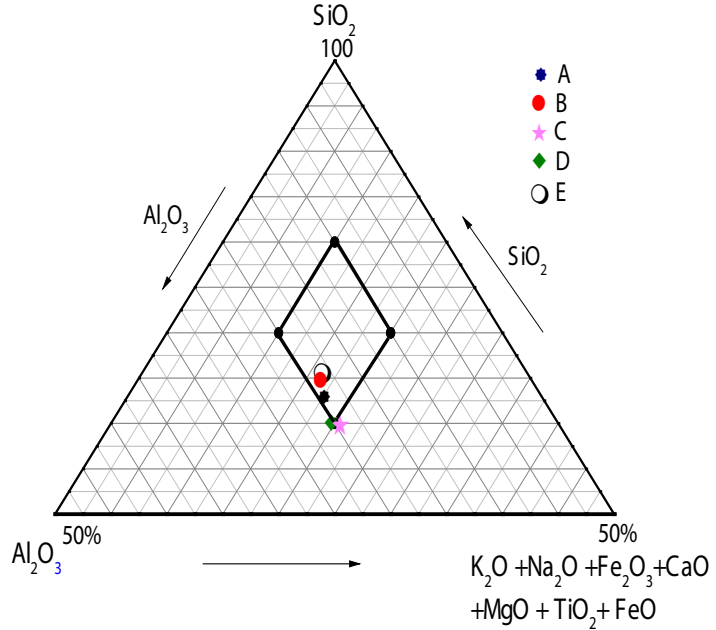

Figura 2: Diagrama ternário das composições das formulações.

[Figure 2: Ternary diagram of the formulations compositions.]

Com as amostras verdes foram determinadas as seguintes propriedades tecnológicas: retração linear de secagem (RLs) e massa específica aparente após secagem (Mea ${ }_{\mathrm{s}}$.

Ensaios tecnológicos realizados com os corpos de prova após queima: em virtude da falta de normas específicas para análise dos agregados de argila, foram utilizados procedimentos adaptados da produção de cerâmica tradicional e das britas tradicionais para avaliação das propriedades de resistência mecânica, absorção de água e massa específica. Absorção de água: os corpos de prova após queima foram submetidos ao teste de absorção de água (AA) com imersão em água fervente por $2 \mathrm{~h}$ segundo a norma ASTM C-20-2005 [22], cujos resultados podem ser expressos pela Equação F, em que $m_{1}$ é a massa seca e $m_{2}$ a massa saturada:

$$
\mathrm{AA}=\left[\left(\mathrm{m}_{2}-\mathrm{m}_{1}\right) / \mathrm{m}_{1}\right] \cdot 100
$$

Massa especifica aparente (Meaq): foi determinada por imersão em mercúrio pelo método de Arquimedes. Resistência à compressão: a resistência de agregados naturais é obtida através da extração de testemunhos da rocha. A resistência à compressão destes corpos de prova é realizada de acordo com a norma NM 101:96 [23]. Como neste trabalho visou-se produzir agregados que possam ser comparados com a brita, optou-se em utilizar esta mesma norma. A tensão de ruptura à compressão (TRC) após queima foi obtida em um tensiômetro da Instron $3763 \mathrm{com}$ velocidade de $0,3 \mathrm{~mm} / \mathrm{min}$. Microscopia eletrônica de varredura: com o objetivo de analisar a morfologia das amostras que apresentaram melhores resultados de caracterização tecnológica após queima a $1120{ }^{\circ} \mathrm{C}$, foram realizadas imagens das formulações das massas pela técnica de microscopia eletrônica de varredura (MEV) em um microscópio Jeol, JSM-6510LV.

\section{RESULTADOS E DISCUSSÃO}

A Tabela II mostra os resultados da análise química das argilas investigadas. As argilas foram constituídas, principalmente de $\mathrm{SiO}_{2}$ e $\mathrm{Al}_{2} \mathrm{O}_{3}$ com elevados teores de 
Tabela II - Composições químicas (\% em massa) das argilas determinadas por FRX.

[Table II - Chemical compositions (wt\%) of clays determined by X-ray fluorescence.]

\begin{tabular}{cccccccccccccc}
\hline & $\mathrm{SiO}_{2}$ & $\mathrm{Al}_{2} \mathrm{O}_{3}$ & $\mathrm{Fe}_{2} \mathrm{O}_{3}$ & $\mathrm{CaO}$ & $\mathrm{K}_{2} \mathrm{O}$ & $\mathrm{Na}_{2} \mathrm{O}$ & $\mathrm{MgO}$ & $\mathrm{Cl}$ & $\mathrm{TiO}_{2}$ & P.F. & Total & $\mathrm{SiO}_{2} / \mathrm{Al}_{2} \mathrm{O}_{3}$ & $\mathrm{Na}_{2} \mathrm{O}+\mathrm{K}_{2} \mathrm{O}$ \\
\hline $\mathrm{PIN}$ & 53,7 & 16,5 & 6,6 & 7,0 & 3,2 & 1,3 & 2,7 & 0,2 & 0,0 & 8,8 & 100,0 & 3,25 & 4,5 \\
$\mathrm{IN}$ & 65,2 & 15,3 & 5,3 & 0,7 & 4,3 & 1,6 & 2,7 & 0,2 & 0,9 & 3,8 & 100,0 & 4,26 & 5,9 \\
$\mathrm{MA}$ & 62,3 & 17,1 & 5,6 & 2,4 & 1,6 & 2,9 & 1,6 & 0,3 & 0,7 & 5,1 & 100,0 & 3,64 & 4,5 \\
\hline
\end{tabular}

$\mathrm{Fe}_{2} \mathrm{O}_{3}$, os quais são elementos associados com estruturas de argilominerais, quartzo e feldspatos, típicos de produtos de cerâmica vermelha [24]. O teor de $\mathrm{SiO}_{2}$ oscilou de 53,7 a $65,2 \%$, enquanto os teores de $\mathrm{Al}_{2} \mathrm{O}_{3}$ de 16,5 a $17,1 \%$. A relação $\left(\mathrm{SiO}_{2} / \mathrm{Al}_{2} \mathrm{O}_{3}\right)$ variou entre valores de 3,25 a 4,26, os quais são mais altos do que os valores clássicos para a caulinita $\left(\mathrm{SiO}_{2} / \mathrm{Al}_{2} \mathrm{O}_{3}: 1,18\right)$ ou para a montmorilonita $\left(\mathrm{SiO}_{2} / \mathrm{Al}_{2} \mathrm{O}_{3}: 2,36\right)$ [25], indicando que quanto maior este coeficiente, maior é a porcentagem de quartzo livre e minerais acessórios presentes nas argilas. $\mathrm{O}$ teor de óxidos alcalinos $\left(\mathrm{Na}_{2} \mathrm{O}+\mathrm{K}_{2} \mathrm{O}\right)$ tem ação fundente e está de acordo com outros trabalhos [26, 27]. A maior porcentagem de óxidos fundentes foi observada na argila IN (5,9\%), que favorece a formação de fase líquida no processo de queima, contribuindo para a redução de poros e aumentando a densificação dos materiais [26]. Por sua vez, o elevado teor de $\mathrm{CaO}$ observado na argila PIN (7\%), é uma indicação que existem carbonatos que são prejudiciais ao fenômeno de densificação $[27,28]$. O teor de $\mathrm{Fe}_{2} \mathrm{O}_{3}$ foi maior que $5 \%$ em todas as argilas, sendo um dos responsáveis pela cor vermelha após queima [28]. Com relação à perda de massa, o maior resultado encontrado foi o da argila PIN (8,8\%), o qual está associado à eliminação da água adsorvida, desidroxilação dos argilominerais, queima da matéria orgânica e a sua maior concentração de $\mathrm{CaCO}_{3}$, que promove a geração do $\mathrm{CO}_{2}$ [27].

A Fig. 3 apresenta os difratogramas de raios $\mathrm{X}$ das amostras estudadas. A análise semiquantitativa dos minerais argilosos está resumida na Tabela III. Os difratogramas mostraram que as argilas foram constituídas principalmente pelos argilominerais caulinita, ilita e $\alpha$-quartzo como fases cristalinas. $\mathrm{O}$ argilomineral caulinita identificado na argila MA apresenta baixa plasticidade e elevada temperatura de fusão [29, 30]. Adicionalmente, traço da argila montmorilonita foi identificado na argila PIN. A Fig. 4 mostra os difratogramas da argila PIN natural e tratado com etileno glicol. Esta comparação foi feita a fim de confirmar a presença da montmorilonita na amostra. A argila natural apresentou pico característico com distância interplanar $\mathrm{d}=14 \AA$, equivalente a $2 \theta=6,2^{\circ}$. A saturação com etileno glicol promoveu a expansão das placas e deslocamento da distância interplanar para $\mathrm{d}=17 \AA$, calculada utilizando a lei de Bragg [26]. Em menor porcentagem, o feldspato estava presente em todas as argilas e foi responsável por fornecer os óxidos alcalinos $\left(\mathrm{K}_{2} \mathrm{O}+\mathrm{Na}_{2} \mathrm{O}\right)$ que favorecem a formação de fase vítrea após queima, contribuindo para redução da porosidade e aumento da densificação em baixas temperaturas [31]. O $\mathrm{CaCO}_{3}$ foi identificado apenas na argila PIN. Este composto dificulta a sinterização devido à liberação do $\mathrm{CO}_{2}$ durante a queima, reduzindo a densificação. A concentração desse

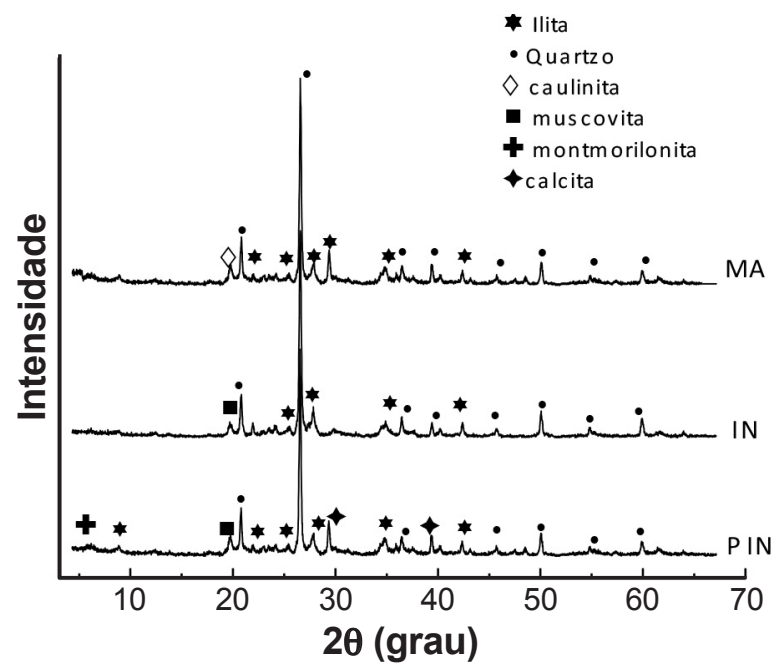

Figura 3: Difratogramas de raios $\mathrm{X}$ das argilas e seus respectivos minerais.

[Figure 3: X-ray diffraction patterns of clays and their minerals.]

Tabela III - Composições mineralógicas das argilas determinadas por difração de raios X.

[Table III - Mineralogical compositions of clays determined by $X R D$.]

\begin{tabular}{cccc}
\hline Mineral & PIN & IN & MA \\
\hline Quartzo & 47,7 & 50,1 & 34,0 \\
Ilita & 27,6 & 29,7 & 35,0 \\
Caulinita & - & - & 9,5 \\
Muscovita & 11,2 & 20,2 & 21,5 \\
Montmorilonita & 0,9 & - & - \\
Calcita & 12,6 & - & - \\
Total & 100 & 100 & 100 \\
\hline
\end{tabular}

mineral modifica as reações químicas e afeta a formação de fase líquida [32]. Durante a etapa de pré-sinterização, os carbonatos decompõem-se acima de $800^{\circ} \mathrm{C}$, porém, nas argilas estudadas, esse fenômeno ocorreu entre 650 e $700^{\circ} \mathrm{C}$ devido provavelmente ao grau de cristalinidade da calcita ou ao tamanho da partícula [33].

A Fig. 5 apresenta um diagrama desenvolvido em [34] que relaciona a porcentagem de partículas $>20 \mu \mathrm{m}$ com partículas $<2 \mu \mathrm{m}$, a partir de argilas utilizadas na Itália para produção de agregados sintéticos. A fração de finos $(<2 \mu \mathrm{m})$ corresponde à fração que confere plasticidade necessária para conformar os produtos e as argilas investigadas estão dentro da faixa recomendada de 25 a $55 \%$. A fração $>20 \mu \mathrm{m}$ corresponde à parte grossa que é necessária ser moída antes 


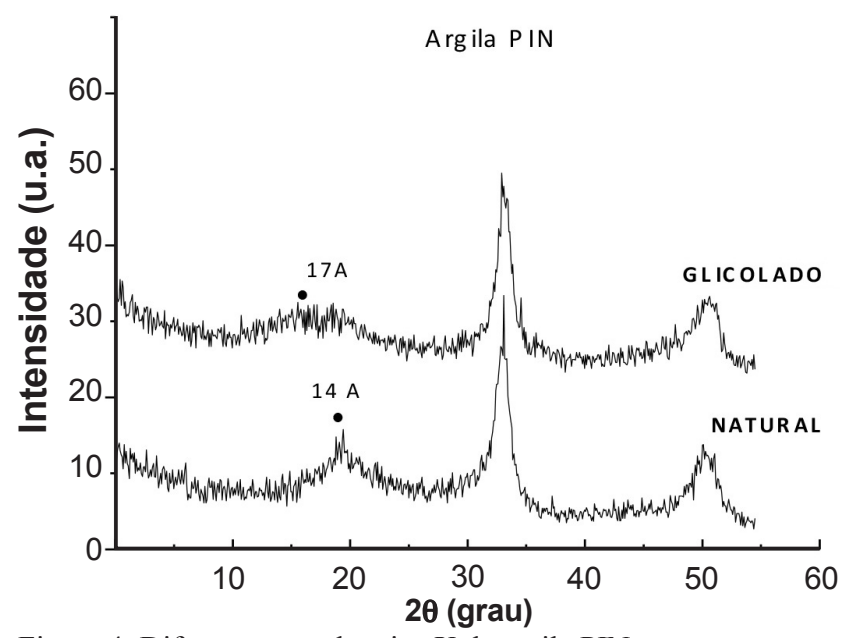

Figura 4: Difratogramas de raios $\mathrm{X}$ da argila PIN.

[Figure 4: X-ray diffraction patterns of the PIN clay.]

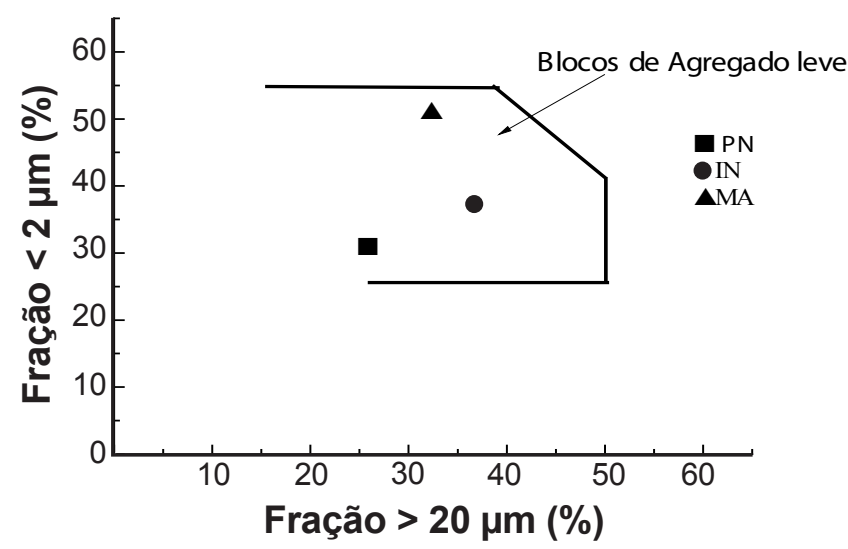

Figura 5: Diagrama de distribuição granulométrica.

[Figure 5: Particle size distribution diagram.]

da utilização [35], e as argilas em estudo também atenderam a faixa proposta no diagrama de 25 a $50 \%$.

A Tabela IV mostra dados da distribuição granulométrica das argilas PIN, IN e MA. A fração de finos $(<2 \mu \mathrm{m})$ confere maior área específica, favorecendo o desenvolvimento da plasticidade, obtendo-se maior resistência mecânica dos corpos conformados a verde [36]. Em razão disso, os canais internos são reduzidos e podem dificultar a eliminação da água durante o processo de secagem [36]. As áreas específicas determinadas através do método de BET são também apresentadas na Tabela IV. Os valores observados são compatíveis com os previamente relatados para argilas cauliníticas $\left(10-20 \mathrm{~m}^{2} / \mathrm{g}\right)$, ilíticas $\left(65-100 \mathrm{~m}^{2} / \mathrm{g}\right)$ e montmoriloníticas $\left(50-800 \mathrm{~m}^{2} / \mathrm{g}\right)$ [25]. A argila MA apresentou maior resultado de área específica $\left(135,3 \mathrm{~m}^{2} / \mathrm{g}\right)$, provavelmente devido à maior porcentagem de matéria orgânica e partículas $<2 \mu \mathrm{m}$, o que pode favorecer o empacotamento das partículas [37]. A argila MA apresentou maior capacidade de troca de cátions $(17,3 \mathrm{meq} / 100)$, provavelmente devido à maior porcentagem de ilita nesta amostra. Por outro lado, o maior teor de matéria orgânica foi observado para a amostra MA (3,3\%), cujo valor aceitável para ciclos rápidos é da ordem de $0,1 \%$ [38], sob risco de gerar coração negro com consequente deformação após queima.

O índice de plasticidade (IP) das argilas também é apresentado na Tabela IV. Segundo [39], materiais que apresentam IP entre 1 e 7\% são considerados fracamente plásticos, de 7 a 15\% são medianamente plásticos e acima de $15 \%$ altamente plásticos, sendo que essas diferenças estão relacionadas com a distribuição do tamanho de partículas. A elevada plasticidade favorece a conformação de produtos com uma maior resistência mecânica após prensagem. Alguns autores afirmam que o IP ideal para a produção cerâmica deve oscilar de 10 a $30 \%$ [40, 41]. Dondi [34] estabeleceu que o valor mínimo do IP para conformação de cerâmica deve ser $15 \%$. Os valores de IP apresentados na Tabela IV variaram de 9 a $16 \%$. A argila IN (IP=9\%) apresentou baixo índice

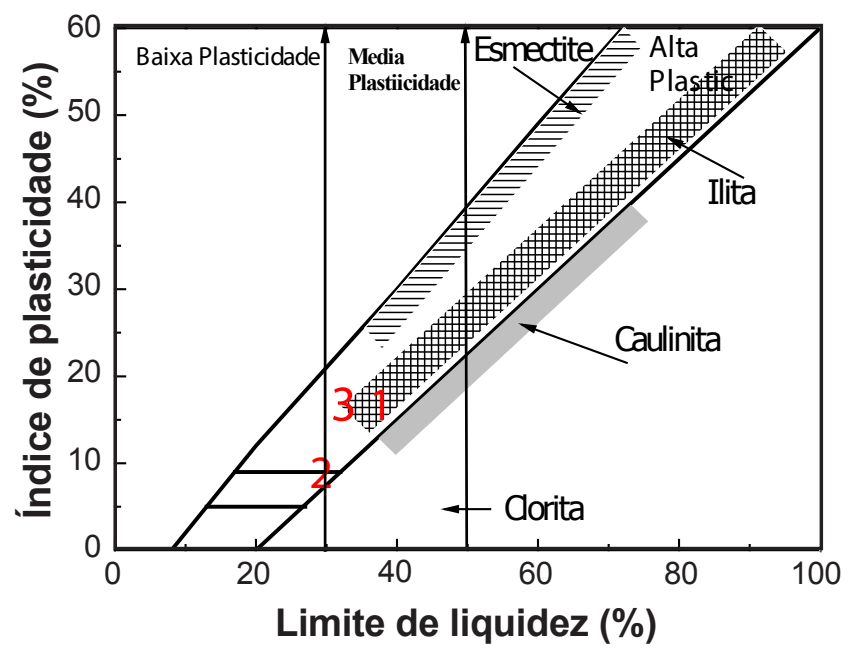

Figura 6: Resultados de índice de plasticidade plotados no diagrama de Holtz e Kovacs [25].

[Figure 6: Results of plasticiy index plotted in Holtz and Kovacs diagram [25].]

Tabela IV - Características físicas das argilas investigadas.

[Table IV - Physical characteristics of the investigated clays.]

\begin{tabular}{cccccccc}
\hline Amostra & $\begin{array}{c}\text { IP } \\
(\%)\end{array}$ & $\begin{array}{c}\text { Fração argila, } \\
<2 \mu \mathrm{m}(\%)\end{array}$ & $\begin{array}{c}\text { Fração silte, } \\
2-60 \mu \mathrm{m}(\%)\end{array}$ & $\begin{array}{c}\text { Fração areia, } \\
>60 \mu \mathrm{m}(\%)\end{array}$ & $\begin{array}{c}\mathrm{BET} \\
\left(\mathrm{m}^{2} / \mathrm{g}\right)\end{array}$ & $\begin{array}{c}\text { CTC } \\
(\mathrm{meq} / 100)\end{array}$ & $\begin{array}{c}\text { MO } \\
(\%)\end{array}$ \\
\hline PIN & 15 & 25,1 & 66,4 & 8,5 & 74,3 & 9,5 & $1,8 \pm 0,1$ \\
IN & 9 & 39,7 & 39,2 & 21,1 & 98,6 & 12,6 & $1,4 \pm 0,2$ \\
MA & 16 & 30,1 & 39,3 & 30,6 & 135,3 & 17,3 & $3,3 \pm 0,1$ \\
\hline
\end{tabular}

BET - área específica; $C T C$ - capacidade de troca de cátions; $M O$ - matéria orgânica. 
de plasticidade devido provavelmente ao elevado teor de quartzo e minerais acessórios como muscovita, identificados no difratograma de raios X. A argila MA apresentou alta plasticidade $(\mathrm{IP}=16 \%)$, devido provavelmente à sua maior porcentagem de matéria orgânica. Na Fig. 6, o diagrama de Holtz e Kovacs [25] confirma que a argila IN-2 possui baixa plasticidade, enquanto a PIN-1 e a MA-3 são consideradas de moderada plasticidade.

As Figs. 7a e 7b apresentam os resultados da análise térmica diferencial (DTA) e análise termogravimétrica (TG) das argilas, respectivamente. Foram observados picos endotérmicos com perda de massa abaixo de $100{ }^{\circ} \mathrm{C}$, devido à eliminação de água adsorvida nas argilas IN e MA [41]. $\mathrm{Na}$ faixa de temperaturas de 400 a $600{ }^{\circ} \mathrm{C}$, foram observados picos endotérmicos em todas as amostras, associados à desidroxilação dos argilominerais presentes nas argilas, que consiste na remoção da água estrutural, seguido pela formação de metacaulinita [42]. Pode-se observar que a argila MA apresentou pico exotérmico a $560{ }^{\circ} \mathrm{C}$, indicando a dissociação da matéria orgânica $[42,43]$. Uma perda de massa considerável foi observada para a argila PIN entre 600 e $750{ }^{\circ} \mathrm{C}$, correspondendo possivelmente à decomposição térmica do $\mathrm{CaCO}_{3}$, com formação de $\mathrm{CaO}$ e liberação de $\mathrm{CO}_{2}$, como observado por outros autores para argilas contendo $\mathrm{CaCO}_{3}$ [33]. Acima de $1100{ }^{\circ} \mathrm{C}$, as curvas de DTA
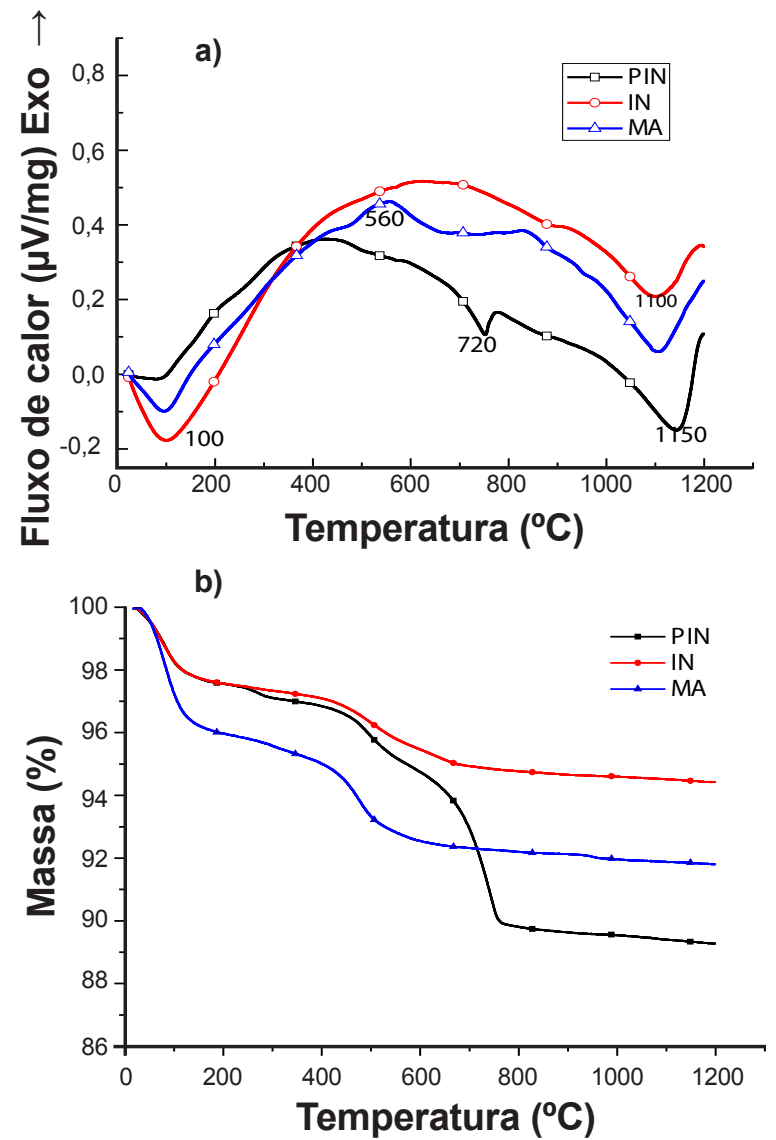

Figura 7: Curvas de análise térmica diferencial (a) e análise termogravimétrica (b) das argilas a uma taxa de $10^{\circ} \mathrm{C} / \mathrm{min}$.

[Figure 7: DTA (a) and TGA (b) curves of clays at a heating rate of $10^{\circ} \mathrm{C} / \mathrm{min}$.] das três amostras apresentaram um evento endotérmico, sem ser acompanhado de perda acentuada de massa registrada na curva de TG. Este evento térmico está possivelmente associado à dissolução do quartzo com formação de uma fase do tipo espinélio. De acordo com [44], essa transformação química deve ser evitada nos processos de queima, por produzir grande retração linear e diminuição da resistência mecânica do produto final.

Na Fig. 8 são apresentados os resultados da análise dilatométrica das amostras. Observou-se que as argilas MA e IN apresentaram pequena retração entre 25 até $200{ }^{\circ} \mathrm{C}$, sobretudo devido à eliminação da água adsorvida ou livre. Nesta faixa de temperatura, a retração ocorreu de forma mais acentuada na argila PIN, provavelmente devido à presença da montmorilonita. A curva foi ainda marcada por aumento de volume brusco entre 573 e $600{ }^{\circ} \mathrm{C}$, devido à mudança alotrópica de quartzo $\alpha$ para $\beta$ em todas as argilas [25]. A partir de $820^{\circ} \mathrm{C}$, teve início a sinterização seguida de acentuada retração nas argilas IN e PIN, provavelmente devido aos elevados teores de óxidos fundentes (Tabela II), que favoreceram a formação de fase líquida [27]. Por outro lado, a argila MA, apesar de apresentar o mesmo teor de fundentes que a argila PIN, somente apresentou o início do processo de retração a partir de $1050^{\circ} \mathrm{C}$. Esse fato pode estar associado à maior área específica $\left(135,3 \mathrm{~m}^{2} / \mathrm{g}\right)$ e elevado teor de matéria orgânica, o que dificulta a saída de gases durante a queima. Para a argila PIN, ficou evidente que o processo de sinterização ocorreu em duas etapas: a $800{ }^{\circ} \mathrm{C}$, logo após a dissociação do $\mathrm{CaCO}_{3}$, e após $1150{ }^{\circ} \mathrm{C}$ quando teve início a formação de fase líquida [24].

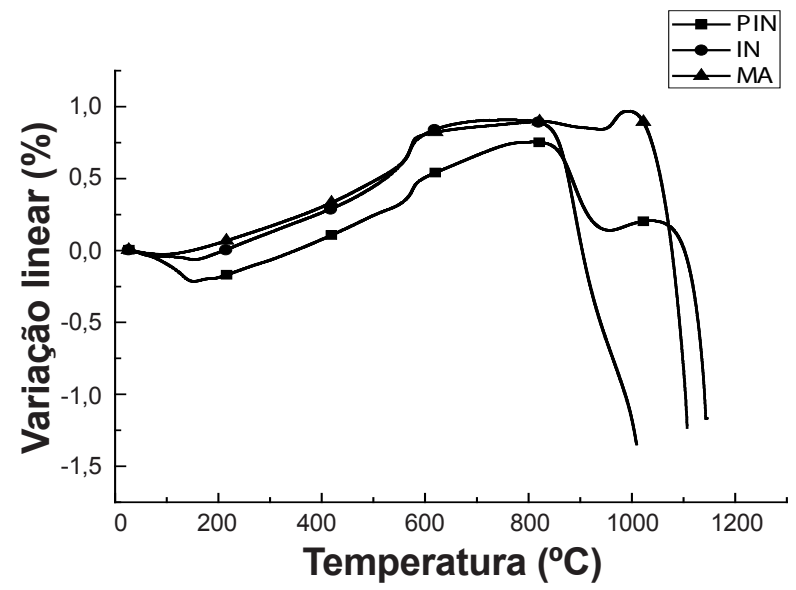

Figura 8: Curvas dilatométricas das argilas a uma taxa de aquecimento de $10^{\circ} \mathrm{C} / \mathrm{min}$.

[Figure 8: Dilatometric curves of clays at a heating rate of $10^{\circ} \mathrm{C} / \mathrm{min}$.]

AFig. 9 mostra a retração dos corpos de prova queimados, em função da temperatura de queima. À medida que cada argila atingiu a temperatura que iniciou a sinterização a retração tendeu a aumentar, conforme curvas dilatométricas apresentadas na Fig. 8. Este comportamento está relacionado ao maior grau de sinterização e densificação em função da redução do volume dos corpos de prova [31]. A argila 


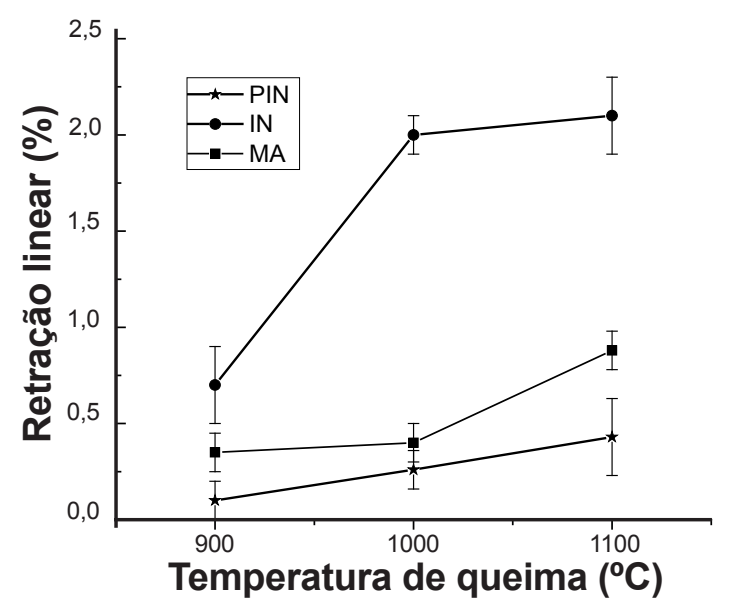

Figura 9: Retração linear dos corpos de prova após queima. [Figure 9: Linear shrinkage of the specimens after firing.]

IN apresentou maior retração na temperatura de $1100{ }^{\circ} \mathrm{C}$, indicando maior variação dimensional do produto acabado.

Na Fig. 10 são mostrados os resultados da densidade, calculados em função da evolução da variação das dimensões das argilas obtidas durante o ensaio de dilatometria. A densidade do corpo cerâmico queimado apresentou correlação direta com a absorção de água, massa específica aparente e resistência mecânica à compressão. Quanto maior a densificação, maiores são a resistência mecânica e massa específica aparente, além de apresentar menor absorção de água e porosidade [3]. Observou-se que para todas as argilas inicialmente à medida que a temperatura aumentou a densidade diminuiu, sobretudo devido à eliminação da água livre, desidroxilação das argilas e queima da matéria orgânica. Vale destacar que a densidade começou a aumentar na amostra $\mathrm{IN}$ a $820^{\circ} \mathrm{C}$, devido à sua maior quantidade de óxidos fundentes, enquanto a PIN só iniciou a $950{ }^{\circ} \mathrm{C}$ e $\mathrm{MA}$ a $1020{ }^{\circ} \mathrm{C}$. A maior densidade foi obtida na argila IN $\left(2,32 \mathrm{~g} / \mathrm{cm}^{3}\right)$.

A Fig. 11 apresenta os resultados dos ensaios das argilas após queima a 900,1000 e $1100{ }^{\circ} \mathrm{C}$. A Fig. 11a apresenta a evolução da absorção de água (AA) em função da temperatura de queima. Pode-se observar que, para todas as amostras estudadas, a absorção diminuiu à medida que

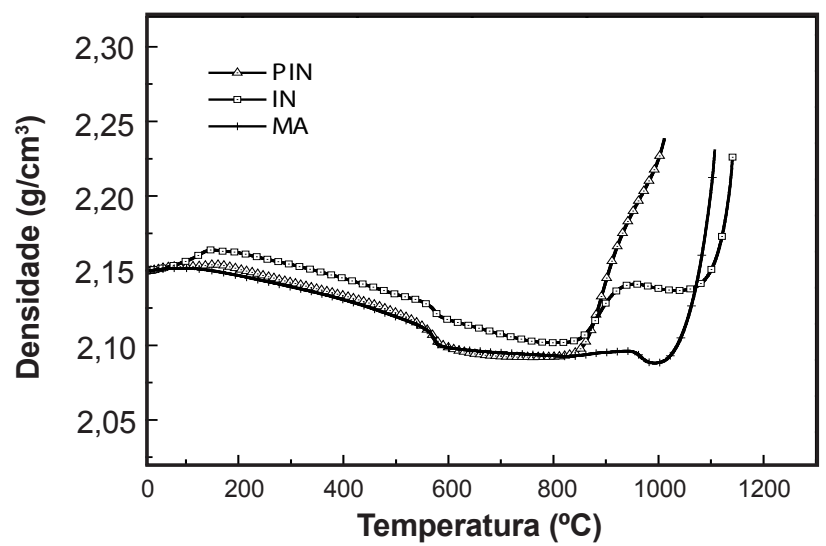

Figura 10: Densidade em função da temperatura. [Figure 10: Density as a function of temperature.]

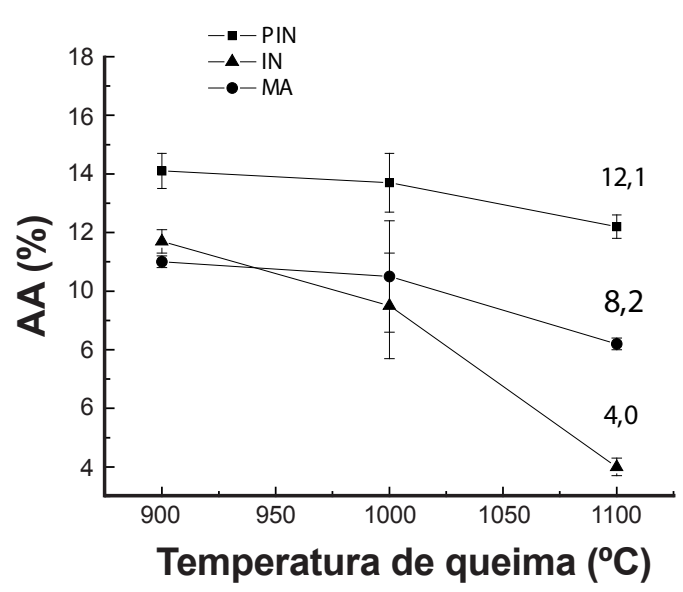

a)

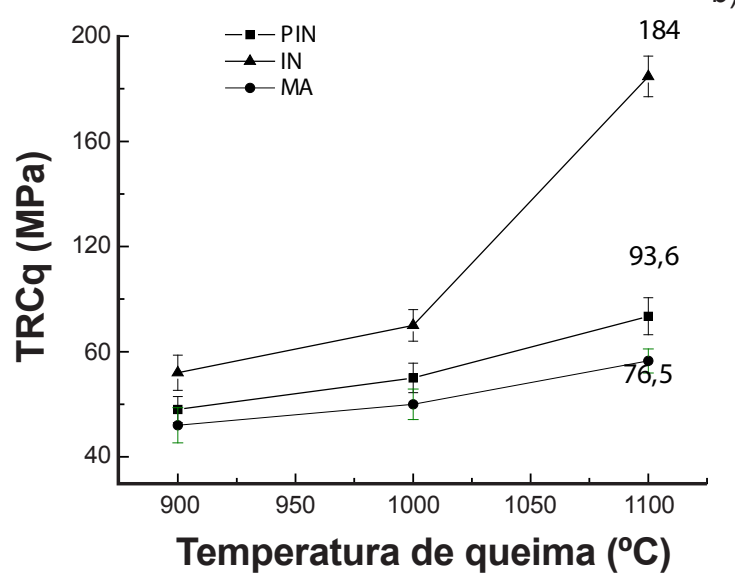

Figura 11: Resultados de absorção de água (a) e tensão de ruptura à compressão (b) em função da temperatura de queima.

[Figure 11: Results of water absorption (a) and compressive strength (b) as a function of firing temperature.]

se aumentou a temperatura, o que se deve ao maior grau de densificação e consequente redução dos poros das argilas [45]. Os menores resultados de absorção de água foram obtidos para as amostras queimadas a $1100{ }^{\circ} \mathrm{C}$, com AA de IN $(4,0 \%)$, seguido da MA (8,2\%) e PIN (12,2\%). A menor absorção de água da IN deveu-se à sua maior quantidade de óxidos fundentes, conforme Tabela II. Considerando que o valor desejável para a absorção de água é próximo de zero, a argila IN é a que mais se aproximou da meta proposta. A absorção de água teve correlação direta com a tensão de ruptura à compressão; quanto menor a absorção de água, maior foi a tensão de ruptura à compressão (TRC). A Fig. 11b apresenta os resultados de TRC. À temperatura de $1100{ }^{\circ} \mathrm{C}$, a argila IN apresentou maior TRC (184 MPa), o qual se aproximou de uma brita, enquanto os valores observados para as argilas PIN e MA foram, respectivamente, 93 e $76 \mathrm{MPa}$, bem abaixo do padrão de britas, conforme Tabela I.

A massa específica dos corpos de prova queimados (Meaq) é mostrada na Fig. 12. A argila PIN foi a que apresentou pior desempenho em relação às demais argilas $\left(1,932 \mathrm{~g} / \mathrm{cm}^{3}\right)$, devido à maior porcentagem de $\mathrm{CaO}$ presente, possivelmente devido à geração do $\mathrm{CO}_{2}$, produzindo maior perda ao fogo, aumentando a porosidade e diminuindo a 
massa específica, como mostrado na Tabela III. A elevada massa específica da argila IN $\left(2,288 \mathrm{~g} / \mathrm{cm}^{3}\right)$ deveu-se ao elevado teor de óxidos fundentes (Tabela II).

Em seguida foram elaboradas formulações de massa com as argilas, conforme mostrado na Tabela V. Os resultados da análise química das misturas são mostrados na Tabela VI. As massas que apresentam maior teor de óxidos

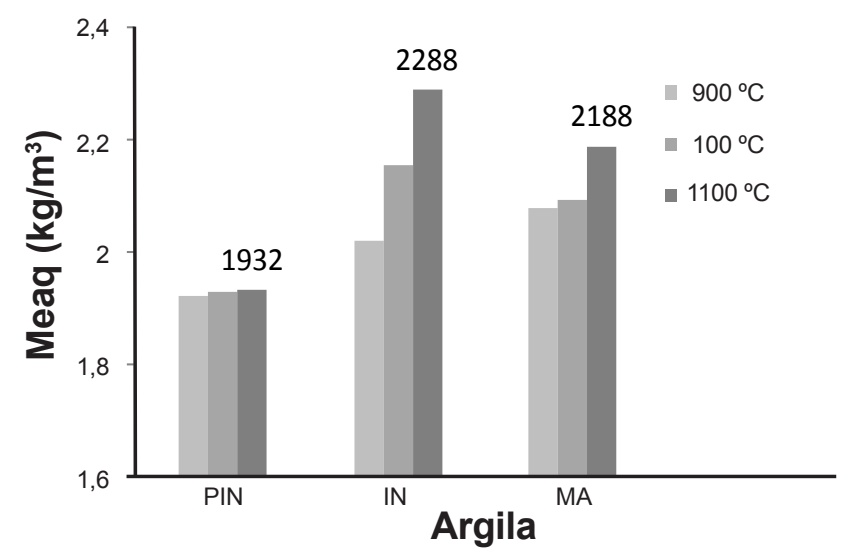

Figura 12: Massa específica das argilas após queima (Meaq). [Figure 12: Specific mass of fired clays (Meaq).]

Tabela V - Proporção das argilas (\% em massa) nas formulações utilizadas para preparação dos corpos de prova. [Table V-Fractions of clays in formulations used to prepare ceramic bodies $(w t \%)$.]

\begin{tabular}{cccccc}
\hline Matéria-prima & A & B & C & D & E \\
\hline IN & 50 & 50 & - & 20 & 60 \\
PIN & 50 & - & 50 & 60 & 20 \\
MA & - & 50 & 50 & 20 & 20 \\
\hline
\end{tabular}

Tabela VI - Resultados da análise química das massas (\% em massa).

[Table VI - Chemical analysis results of the ceramic formulations (wt\%).]

\begin{tabular}{cccccc}
\hline & $\mathrm{A}$ & $\mathrm{B}$ & $\mathrm{C}$ & $\mathrm{D}$ & $\mathrm{E}$ \\
\hline $\mathrm{P.F}$ & 6,4 & 4,6 & 6,8 & 7,0 & 5,1 \\
$\mathrm{SiO}_{2}$ & 58,4 & 62,8 & 57,1 & 56,7 & 61,3 \\
$\mathrm{Al}_{2} \mathrm{O}_{3}$ & 16,3 & 17,3 & 17,2 & 16,6 & 16,7 \\
$\mathrm{CaO}$ & 3,9 & 1,5 & 4,8 & 4,9 & 2,4 \\
$\mathrm{Fe}_{2} \mathrm{O}_{3}$ & 5,9 & 5,4 & 6,0 & 6,1 & 5,6 \\
$\mathrm{~K}_{2} \mathrm{O}$ & 3,7 & 3,0 & 2,4 & 3,1 & 3,5 \\
$\mathrm{MgO}$ & 2,6 & 2,0 & 2,1 & 2,4 & 2,5 \\
$\mathrm{Na}_{2} \mathrm{O}$ & 1,3 & 2,2 & 2,0 & 1,6 & 1,7 \\
$\mathrm{SO}_{3}$ & 0,5 & 0,6 & 0,4 & 0,3 & 0,6 \\
$\mathrm{P}_{2} \mathrm{O}_{5}$ & 0,2 & 0,2 & 0,2 & 0,2 & 0,2 \\
$\mathrm{Cl}$ & 0,2 & 0,0 & 0,1 & 0,2 & 0,1 \\
$\mathrm{MnO}$ & 0,2 & 0,5 & 0,3 & 0,2 & 0,2 \\
$\mathrm{Total}$ & 99,9 & 100,1 & 100,0 & 100,0 & 100,1 \\
$\mathrm{Na}_{2} \mathrm{O}+\mathrm{K}_{2} \mathrm{O}$ & 5,1 & 5,2 & 4,4 & 4,7 & 5,2 \\
\hline
\end{tabular}

fundentes $\left(\mathrm{Na}_{2} \mathrm{O}+\mathrm{K}_{2} \mathrm{O}\right)$ foram $\mathrm{B}$ e $\mathrm{E}(5,2 \%)$. Considerando a correlação entre o teor de fundentes, retração e resistência mecânica, espera-se que essas amostras apresentem os melhores resultados de caracterização tecnológica, com baixo valor de AA e elevado valor de TRC. Outro fator que pode influenciar na sinterização é o teor de $\mathrm{CaCO}_{3}$ presente nas argilas. Nos diagramas ternários tradicionais, o $\mathrm{CaCO}_{3}$ $\mathrm{em}$ teor de até $3 \%$ atua com fundente. Acima deste valor, ocorre formação de poros superior à formação de fase líquida tornando a peça porosa. Durante a etapa de pré-sinterização, os carbonatos decompõem-se acima de $800{ }^{\circ} \mathrm{C}$, porém, nas argilas estudadas, esse fenômeno ocorreu entre 650 e $700^{\circ} \mathrm{C}$, conforme visto em outros trabalhos [46].

Na Fig. 13 são mostrados os difratogramas de raios $\mathrm{X}$ das massas natural e após queima, que foram similares a outros trabalhos [45, 46]. Nas formulações B e E, na forma natural, estavam presentes os argilominerais ilita e caulinita, que são responsáveis pela plasticidade garantindo a resistência mecânica a verde. Destaca-se a presença de traço de montmorilonita na formulação $\mathrm{E}$, que apresenta elevada plasticidade e dificulta a fase de secagem. Foi ainda identificada a muscovita como acessório, que fornece os óxidos fundentes e o quartzo que atua reduzindo a plasticidade e que juntamente com outros óxidos forma a
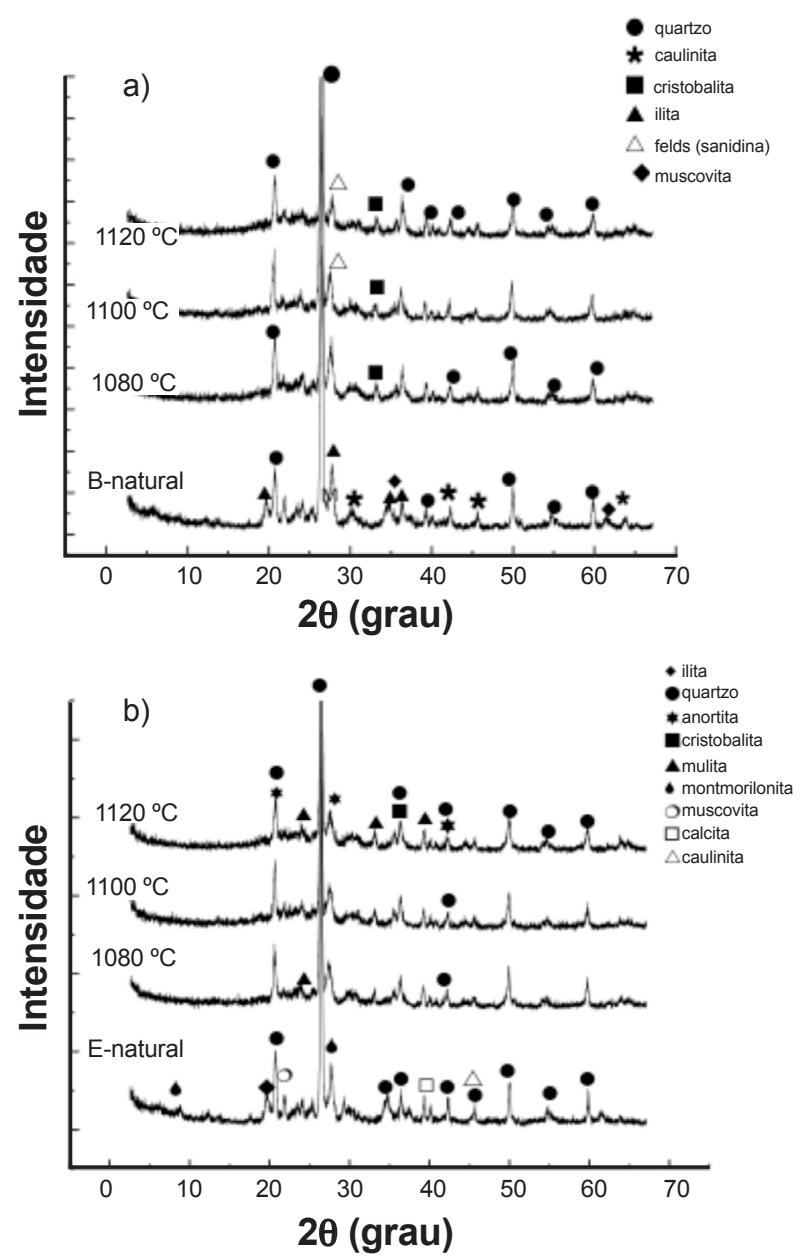

Figura 13: Difratogramas de raios X das formulações B (a) e E (b). [Figure 13: XRD patterns of formulations $B(a)$ and $E(b)$.] 

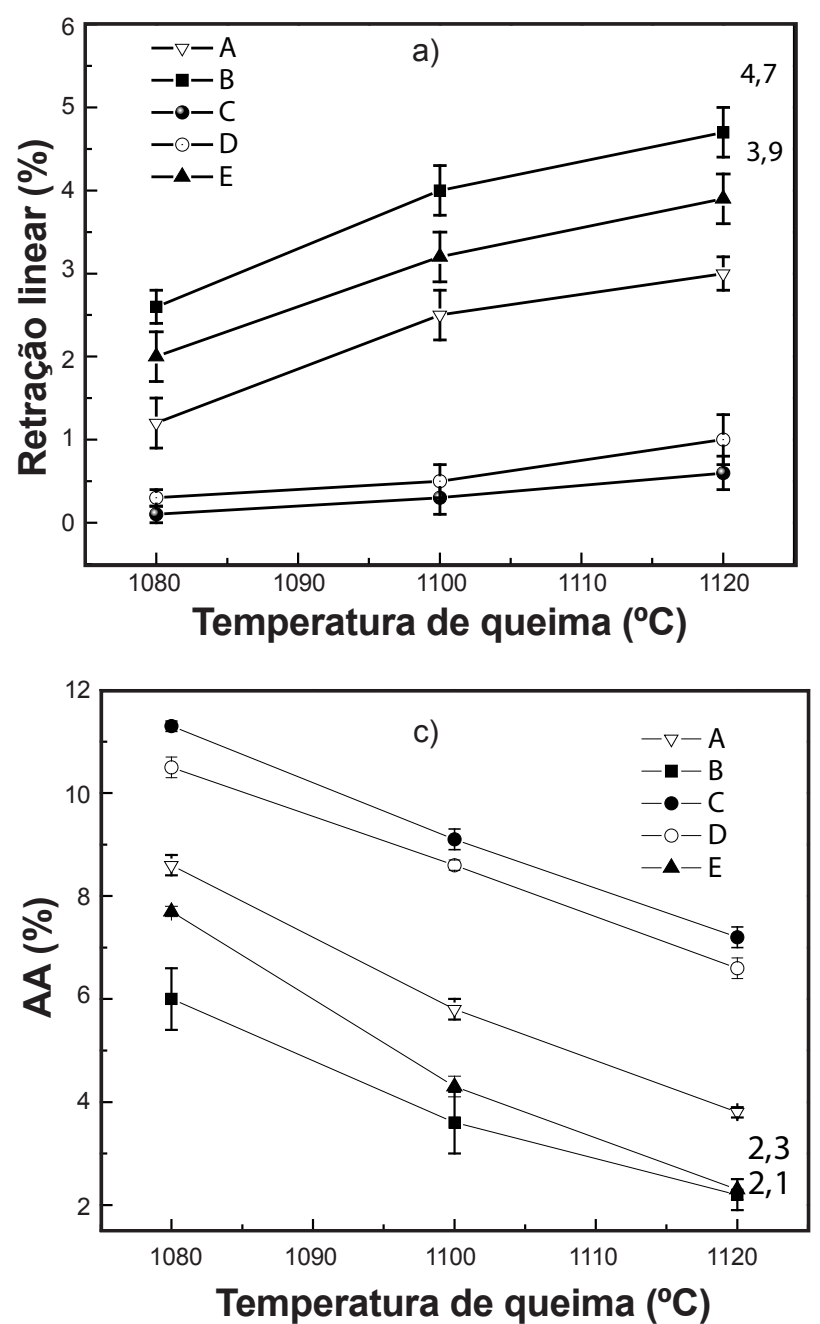
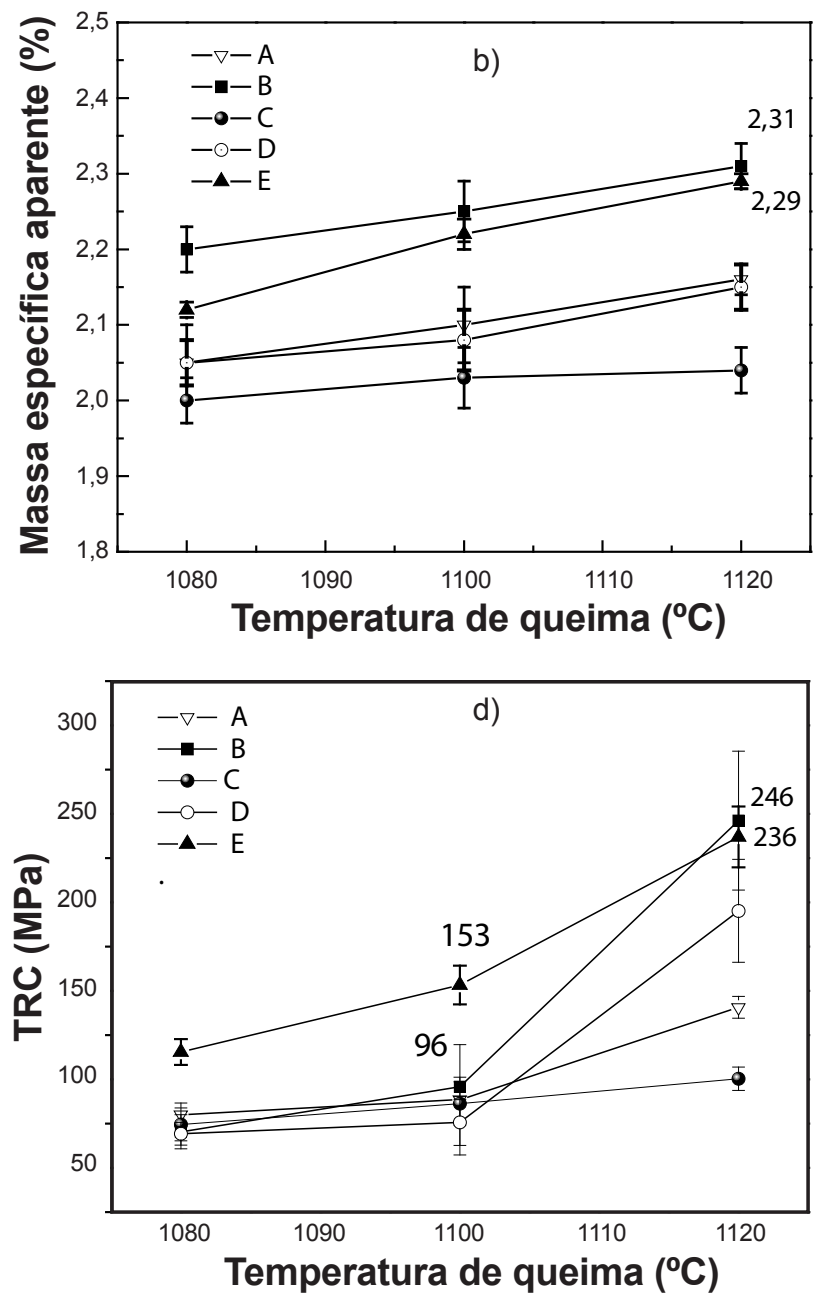

Figura 14: Resultados de retração linear (a), massa específica (b), absorção de água (c) e tensão de ruptura à compressão (d) das massas em função da temperatura de queima.

[Figure 14: Results of linear shrinkage (a), specific mass (b), water absorption (c) and compressive strength (d) of the mixtures as a function of firing temperature.]

fase líquida. $\mathrm{Na}$ formulação $\mathrm{E}$ foi identificado ainda o $\mathrm{CaCO}_{3}$ que possui ação fundente em determinadas temperaturas quando utilizado em até 3\%. Acima deste valor favorece a formação de poros, reduzindo a densidade da cerâmica [31]. De acordo com os difratogramas, após queima, em ambas formulações em todas as temperaturas, foram identificados quartzo, cristobalita e feldspato na forma de sanidina, com destaque para anortita encontrada na massa $E$, que é um silicato de cálcio formado sobretudo devido à presença do $\mathrm{CaO}$ na formulação [47].

A Fig. 14 mostra os resultados dos ensaios de retração linear (RLq), massa específica (Meq), absorção de água (AA) e tensão de ruptura à compressão (TRC) das amostras das formulações de massa. De acordo com a Fig. 14a, à medida que se aumentou a concentração da argila IN as retrações maiores ocorreram nas massas $\mathrm{B}$ e E. Essas formulações possuíram maior quantidade de $\mathrm{Na}_{2} \mathrm{O}+\mathrm{K}_{2} \mathrm{O}$, aliada à baixa perda ao fogo e baixa porcentagem de $\mathrm{CaO}$, conforme mostrado na Tabela VI. Proporcionalmente, os valores de massa específica apresentados na Fig. 14b, nas massas B e E, foram os mais elevados, bem como menores foram os resultados de absorção de água mostrados na Fig. $14 \mathrm{c}$ e maiores os resultados de resistência à compressão mostrados na Fig. 14d. De acordo com a Fig. 14c, à medida que se aumentou a temperatura de queima, a absorção de água foi reduzindo; na temperatura de $1120^{\circ} \mathrm{C}$ foi observada menor absorção de água nas massas B (2,1\%) e E (2,3\%), devido à formação de fase líquida que preencheu os poros aumentando a densificação. Quanto aos resultados da tensão de ruptura à compressão (TRC, Fig. 14d), destacam-se as massas B e C que apresentaram maiores resultados a $1120^{\circ} \mathrm{C}$, com valores de TRC de 236 e $246 \mathrm{MPa}$, respectivamente, de acordo com o padrão de uma brita (Tabela I).

Nas Figs. 15a e 15b são mostradas, respectivamente, as imagens de microscopia eletrônica de varredura para as formulações de massas B e E queimadas a $1120^{\circ} \mathrm{C}$. Considerando que estas amostras apresentaram os melhores resultados de absorção de água e resistência mecânica à compressão, nesta temperatura, ocorreu maior formação de fase líquida, a qual se distribuiu melhor pela estrutura, promovendo redu- 

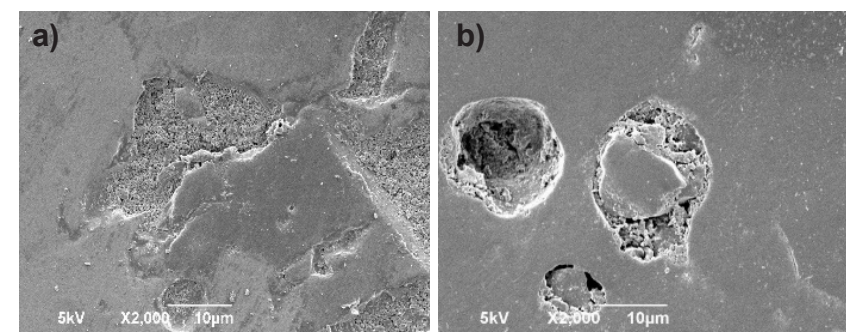

Figura 15: Micrografias obtidas por microscopia eletrônica de varredura das massas B (a) e E (b) queimadas a $1120^{\circ} \mathrm{C}$.

[Figure 15: SEM micrographs of mass $B(a)$ and $E$ (b) fired at $1120^{\circ} \mathrm{C}$.]

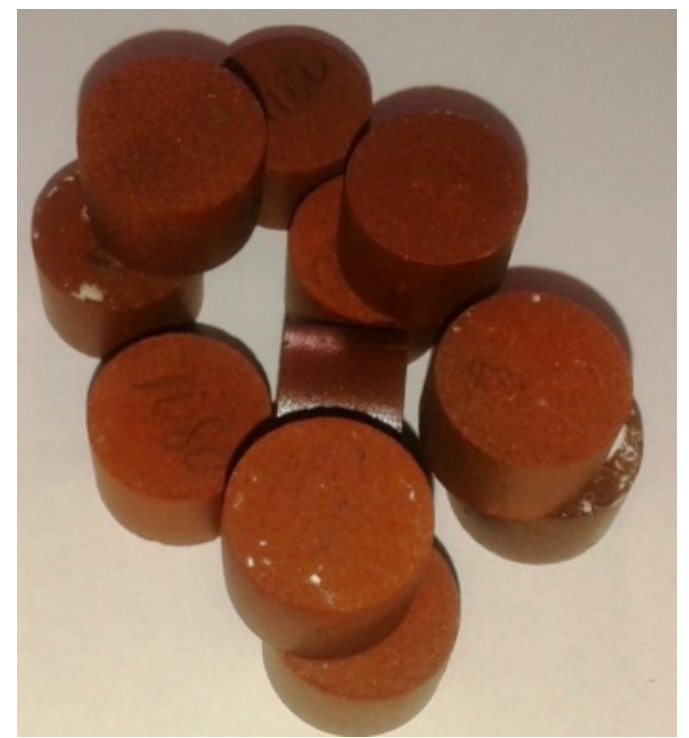

Figura 16: Fotografia dos corpos de prova da mistura E após sinterização a $1120^{\circ} \mathrm{C}$.

[Figure 16: Photograph of the ceramic bodies of formulation E after firing at $1120^{\circ} \mathrm{C}$ for $15 \mathrm{~min}$.]

ção do volume de poros. Adicionalmente, ocorreu acréscimo da resistência mecânica e da massa específica. Vale destacar que na massa $\mathrm{E}$ foi observada a presença de poros resultantes da dissociação do $\mathrm{CaCO}_{3}$ deixados na liberação do $\mathrm{CO}_{2}$ [31]. Na Fig. 16 são mostrados os corpos de prova produzidos de agregado sintético calcinado pelo método de prensagem.

\section{CONCLUSÕES}

No presente trabalho, foram exploradas as propriedades de agregados sintéticos de argila calcinada como alternativa ao uso de britas e seixos de rios, cuja exploração traz impactos significativos ao meio ambiente. A argila IN apresentou excelente potencial para produzir agregados calcinados de argilas para produção de concreto leve de baixa absorção de água e elevada resistência mecânica à compressão, sobretudo se queimada na faixa de temperatura de 1100 a $1120^{\circ} \mathrm{C}$. A melhor densificação dessa argila foi associada à maior quantidade de óxidos fundentes $\left(\mathrm{Na}_{2} \mathrm{O}+\mathrm{K}_{2} \mathrm{O}\right)$ fornecidos pelo argilomineral ilita e muscovita. A argila
PIN apresentou elevada plasticidade, o que é fundamental para conformação por prensagem de materiais cerâmicos. A elevada absorção de água apresentada após queima a 1100 ${ }^{\circ} \mathrm{C}(12,0 \%)$ foi causada pelo elevado teor de $\mathrm{CaCO}_{3}$ nesta argila. Adicionalmente, a argila PIN misturada na formulação E garantiu maior estabilidade da resistência mecânica na faixa de temperatura de queima de 1100 a $1120^{\circ} \mathrm{C}$. A argila MA, apesar de apresentar baixa absorção de água $(8,2 \%)$ após queima a $1100{ }^{\circ} \mathrm{C}$, apresentou resistência mecânica à compressão insatisfatória (76 MPa), provavelmente devido à maior quantidade de matéria orgânica que retardou o processo de sinterização identificado no ensaio de análise dilatométrica. Com relação à meta proposta para produção de agregados de argila calcinados com características próximas de uma brita, a formulação de massa $\mathrm{E}(60 \% \mathrm{IN}$, $20 \%$ PIN e $20 \%$ MA) queimada na temperatura de $1120{ }^{\circ} \mathrm{C}$ foi a que apresentou os melhores resultados de absorção de água $(2 \%)$, resistência à compressão $(236 \mathrm{MPa})$ e massa específica aparente $\left(2,31 \mathrm{~g} / \mathrm{cm}^{3}\right)$, próximos a uma brita gnaisse utilizadas na produção de concreto leve. Testes com concreto leves serão realizados para validação das propriedades obtidas.

\section{REFERÊNCIAS}

[1] Depto. Nac. Pesq. Min., Sumário Mineral, http://www. dnpm.gov.br/dnpm/sumarios/sumario-mineral-2014, acessado em 21.09.2016.

[2] Ass. Nac. Ent. Prod. Agreg. Constr., http://www.anepac. org.br/agregados/mercado, acessado em 20.09.2016.

[3] T. Huang, Feng Shi, Hiroki Tanikawa, Jinling Fei, Ji Han, Conserv. Recy. 72 (2013) 91.

[4] D.C. Bacci, P.M.B. Landim, S.M. Eston, Rev. Escola Minas Ouro Preto 59, 1 (2006) 47.

[5] C. Ingrao, A.L. Giudice, C. Tricase, C.M.R. Rana, J. Clean. Prod. 75 (2014) 195.

[6] A.C.L. da Silva, C.A. Frota, Cerâmica 59, 352 (2013) 508.

[7] B. Santis, J.A. Rossignolo, Rev. Matéria 20, 2 (2015) 399.

[8] J.A. Rossignolo, M.V.C. Agnesini, J.A. Moris, Cem. Concr. Compos. 25 (2003) 77.

[9] E.M. Cabral, R.J. de Sá, R.K. Vieira, R.P. Vasconcelos, Cerâmica 54, 332 (2008) 404.

[10] Ass. Nac. Fabr. Cerâm. Revest., Louça Sanit. Congên., http://www.anfacer.org.br/, acessado em 02.01.2016.

[11] Ass. Nac. Fabr. Cerâm. Vermelha, http://portal.anicer. com.br/setor/, acessado em 10.01.2016.

[12] G.C. Isaia, "Concreto: ensino, pesquisa e realizações", IBRACON, S. Paulo (2005).

[13] Inst. Bras. Geogr. Estat., http://mapas.ibge.gov.br/ fisicos, acessado em 20.12.2015.

[14] ASTM D422-63, "Standard test method for particlesize analysis of soils" (1998).

[15] Ass. Bras. Normas Téc., NBR 6459:84, "Determinação do limite de liquidez".

[16] Ass. Bras. Normas Téc., NBR 7180:84, "Determinação 
do limite de plasticidade".

[17] ASTM C-837, "Standard test method for methylene blue index of clay".

[18] ASTM D 2974, "Standard test methods for moisture, ash, and organic matter of peat and organic soils".

[19] M.N. Rahaman, Ceramic processing and sintering, $2^{\text {nd }}$ Ed., Taylor \& Francis, Missouri (2003) 782.

[20] D. Bartolomeu, M.M.T. Moreno, R.P. da Rocha, Metalurgia Materiais 64, 1 (2011) 63.

[21] A. Monem Mohamed Soltan, W. Achim Kahl, F. Abd El-Raoof, B. Abdel-hamid El-Kaliouby, M. Abdel-Kader Serry, N. Ali Abdel-Kader, J. Clean. Prod. 117 (2016) 139. [22] ASTM C-20-2005, "Standard test methods for apparent porosity, water absorption, apparent specific gravity, and bulk density of burned refractory brick and shapes by boiling water".

[23] NM 101:96, Norma Mercosur, Hormigon, "Ensayo de compression de probetas cilíndricas".

[24] A.C. Alcântara, M.S. Beltrão, H.A. Oliveira, I.F. Gimenez, L.S. Barret, Appl. Clay Sci. 39 (2008) 160.

[25] S. Boussen, D. Sghaqier, F. Chaabani, B. Jamoussi, A. Bennour, Appl. Clay Sci. 123 (2016) 210.

[26] H. Celik, Appl. Clay Sci. 50 (2010) 245.

[27] S.N. Monteiro, Appl. Clay Sci. 27 (2004) 229.

[28] S. Gunasekaran, G. Anbalagan, Bull. Mater. Sci. 30 (2007) 339.

[29] S. Mahmoudi, E. Srasra, F. Zargouni, Appl. Clay Sci. 42 (2008) 125.

[30] E.L. Quahabi, Clay Mineral 49 (2015) 35.

[31] C.P. Santos, H.A. Oliveira, R.M.P.B. Oliveira, Z.S. Macedo, Cerâmica 62, 362 (2016) 147.
[32] P. Cardiano, S. Sergi, C. Stefano, S. Ioppolo, P. Piraino, J. Therm. Anal. Calorim. 91 (2008) 477.

[33] M. Arsenovic, L. Pezo, L. Mancic, A. Radojeviv, Thermochim. Acta 580 (2014) 38.

[34] M. Dondi, B. Fabbri, G. Guarini, Clay Miner. 9, 33 (1998) 33.

[35] F. Hammami-Bem Zaied, R. Abidi, N.Sl Shimi, Al K. Somarin, Appl. Clay Sci. 112-113 (2015) 1.

[36] S. Pracidelli, F.G. Melchiades, Cerâm. Ind. 2, 1/2 (1997) 31.

[37] J.E. Boulingui, C. Nkoumbou, D. Nojya, F. Thomas, J. Yvon, Appl. Clay Sci. 115 (2015) 132.

[38] J.C. Damiani, F. Perez, F.G. Melchiades, A.O. Boschi, Cerâm. Ind. 6, 2 (2001) 12.

[39] S.C. Maestrelli, C.D. Roveri, A.G.P. Nunes, L.M. Faustino, G.F. Aielo, L.P.A. Pinto, C. Manochio, T.M.L. Cal, F.F. Ribeiro, N.A. Mariano, Cerâmica 59, 350 (2013) 242.

[40] P. Souza Santos, Tecnologia de argilas, Edgard Blücher, 1 (1989).

[41] R.S. Macedo, R.R. Menezes, G.A. Neves, H.C. Ferreira, Cerâmica 54, 332 (2008) 411.

[42] P.B. Arabe; O.J. Pejon, Appl. Clay Sci. 114 (2015) 133.

[43] P. Ptacek. D. Kubatova, Powder Technol. 204 (2010) 222.

[44] R.V. Zamudio, C.A. Chavez, J. Cervantes, J. Therm. Anal. Calorim. 104 (2011) 405.

[45] I.P. Brito, E.P. Almeida, G.A. Neves, R.R. Menezes, V.J. Silva, L.N.L. Santana, Cerâmica 61, 360 (2015) 391.

[46] P. Cardiano, S. Sergi, C. Stefano, S. Ioppolo, P. Piraino, J. Therm. Anal. Calorim. 91 (2008) 477.

[47] A. Bennour, S. Mahmoudi, E. Srasra, S. Boussen, N. Htira, Appl. Clay Sci. 115 (2015) 3.

(Rec. 31/05/2016, Rev. 25/09/2016, 29/11/2016, Ac. 29/11/2016) 